\title{
TOKOH WAYANG SEMAR SEBAGAI BUDAYA LOKAL INDONESIA DALAM RANGKA MEMPERKAYA IMAJINASI DAN SUMBER KREATIVITAS DEKAVE
}

\author{
Endro Tri Susdarwono ${ }^{1}$ \\ ${ }^{1}$ Universitas Peradaban \\ ${ }^{1}$ midas999saniscara@gmail.com
}

\begin{abstract}
The purpose of this study is to discuss the Semar puppet characters who are Indonesian local culture as a wealth of imagination and a source of creativity in the creation of visual communication design works. This research is a qualitative research, the type of research uses a comprehensive analytical study and analytical normative approach. Indonesian local culture needs to be embraced into a wealth of imagination and a source of creativity for the process of creating advertising design works. By following the prevailing customs, upholding morality, and prioritizing local cultural wisdom to be later appointed as inspiration, source of ideas and ideas, as well as software to communicate various commercial, social, or moral messages to the target audience, existence A visual communication design work will accentuate people's lives, in the end it is expected to be able to enlighten the thoughts and feelings of human beings who live and fill their lives according to their respective talents. The mysterious Semar wayang figure is also part of the religious mythological figure loved by the Javanese people in particular. Therefore, Semar is considered to have high value and value in wayang as part of Javanese life. So, of course the character Semar will be interesting to study more carefully and more deeply in terms of philosophy in an effort to unravel the mystery that surrounds him.
\end{abstract}

Keywords: local culture; puppet; Semar; visual communication design

\begin{abstract}
Abstrak
Tujuan penelitian ini membahas mengenai tokoh wayang Semar yang merupakan budaya local Indonesia sebagai kekayaan imajinasi dan sumber kreativitas penciptaan karya desain komunikasi visual. Penelitian ini merupakan penelitian kualitatif, tipe penelitiannya menggunakan kajian komprehensif analitis dan pendekatannya normatif analitis. Budaya lokal Indonesia perlu dirangkul menjadi kekayaan imajinasi dan sumber kreativitas bagi proses penciptaan karya desain iklan. Dengan mengikuti perilaku adat istiadat yang berlaku, menjunjung tinggi moralitas, dan mengedepankan kearifan budaya lokal untuk kemudian diangkat menjadi inspirasi, sumber ide, dan gagasan, serta sebagai perangkat lunak untuk mengomunikasikan beragam pesan komersial, sosial, ataupun moral kepada sasaran khalayak yang dibidik, keberadaan sebuah karya desain komunikasi visual akan memberikan aksentuasi perikehidupan masyarakat, ujung-ujungnya diharapkan mampu mencerahkan pemikiran dan perasaan umat manusia yang hidup dan mengisi kehidupannya sesuai dengan talenta masing-masing. Tokoh wayang Semar yang penuh misteri juga merupakan bagian dari tokoh mitologis religious yang disayangi oleh masyarakat Jawa pada khususnya. Oleh karena itu, Semar dianggap memiliki nilai dan berharga tinggi dalam pewayangan sebagai bagian dari kehidupan masyarakat Jawa. Maka, tentu saja tokoh Semar akan menarik untuk dipelajari dengan lebih seksama dan lebih mendalam dari sisi falsafah dalam upaya mengungkap misteri yang menyelubunginya.
\end{abstract}

Kata kunci: budaya lokal; desain komunikasi visual; Semar; wayang 


\section{PENDAHULUAN}

Desain Komunikasi Visual sebagai seni menyampaikan pesan (art of communication) dengan menggunakan bahasa rupa (visual language) yang disampaikan melalui media berupa desain yang bertujuan menginformasikan, mempengaruhi hingga merubah perilaku target yang melihat sesuai dengan tujuan yang diinginkan (Pusat Pendidikan Desain Komunikasi Visual Modern). Desain Komunikasi Visual bertujuan mempelajari konsep-konsep komunikasi serta ungkapan kreatif melalui berbagai media untuk menyampaikan pesan dan gagasan secara visual dengan mengelola elemen-elemen grafis yang berupa bentuk dan gambar, tatanan huruf, serta komposisi warna serta layout (tata letak atau perwajahan). Dengan demikian, gagasan bisa diterima oleh orang atau kelompok yang menjadi sasaran penerima pesan (Herliyani \& Suryana, 2015).

Fenomena penciptaan seni atau proses kreatif menurut Saini KM (2001) masih dianggap sebagai sesuatu yang misterius, dan irasional. Dengan demikian positioningnya berada di luar jangkauan kajian ilmiah. Para seniman dianggap sebagai orang yang mendapatkan bakat alamiah. Ia mampu mencipta karya seni di luar pengendalian diri. Oleh karena itu, ia tidak perlu pemahaman tentang kemampuannya. Dan tidak butuh latihan untuk memelihara ketrampilannya.

Premis semacam itu sulit ditemui di jagat desain komunikasi visual. Sebab dalam aktivitas perancangan desain komunikasi visual, para desainer komunikasi visual senantiasa mendasarkan pada unsur kreativitas dan inovasi. Yakni, suatu proses mental, proses berpikir yang mampu menimbulkan ide baru dan bila diaplikasikan secara praktis akan menghasilkan cara yang lebih efisien.

Keberadaan desain komunikasi visual sangat lekat dengan hidup dan kehidupan kita sehari-hari. Ia tak bisa lepas dari sejarah manusia. Karena ia merupakan salah satu usaha manusia untuk meningkatkan kualitas hidup. Desain komunikasi visual sangat akrab dengan kehidupan manusia. Ia merupakan representasi sosial budaya masyarakat, dan salah satu manifestasi kebudayaan yang berwujud produk dari nilai-nilai yang berlaku pada waktu tertentu. Ia merupakan kebudayaan yang benar-benar dihayati, bukan kebudayaan dalam arti sekumpulan sisa bentuk, warna, dan gerak masa lalu yang kini dikagumi sebagai benda asing terlepas dari diri manusia yang mengamatinya (Tinarbuko, 2015).

Sayangnya, mereka yang ada di industri komunikasi visual memiliki cacat rasa akibat dari kurangnya rasa percaya diri sebagian besar insan kreatif periklanan Indonesia. Mereka merasa gamang untuk merangkul dan memanfaatkan budaya lokal Indonesia agar menjadi pijakan untuk berkarya kreatif secara dahsyat. Padahal dengan mengedepankan budaya lokal, akan menumbuhkan keberagaman sudut pandang komunikasi visual dan berujung pada outcome ide dalam balutan craftsmanship yang "ciamik". Artinya, dalam rangka mencari dan menjadikan 100 persen karya desain komunikasi visual Indonesia perlu kiranya kita memberi perhatian khusus pada aspek kearifan budaya lokal, adat istiadat, dan moralitas.

Budaya lokal akan lebih bermakna karena mampu mendorong semangat kecintaan pada kehidupan manusia dan alam semesta. Sementara teknologi sebagai hasil kebudayaan yang bersifat fisik tanpa spritualitas nilai-nilai yang terkandung dalam adat istiadat,agama, kesenian akan kehilangan fungsi untuk meningkatkan kualitas hidup manusia (Setyaningrum, 2018). Seni tradisi merupakan identitas budaya dari suatu masyarakat tertentu, sebab seni tradisi sangat dipengaruhi oleh kultur masyarakat di suatu lingkungan dan bukan merupakan seniyang menonjolkan seniman atas nama diri sendiri, tapi lebih merupakan perwakilan dari sistem sosial atau sikap kelompok masyarakat (Fauzan \& Nashar, 2017).

Kebudayaan memegang peranan yang sangat penting dalam kehidupan manusia. Sebagaimana yang kita ketahui bahwa peradaban manusia di bumi merupakan hasil dari kebudayaan (Suparno et al, 2018). Semar adalah nama tokoh punakawan paling utama dalam pewayangan Jawa, bahkan juga pada pewayangan di daerah Sunda dan Bali. Tokoh ini dikisahkan sebagai pengasuh sekaligus penasihat para satria dalam pementasan kisahkisah Mahabharata dan Ramayana (Kresna, 2012). Pertama kali penokohan Semar 
ditemukan dalam karya sastra zaman Kerajaan Majapahit berjudul Sudamala. Semar dikisahkan sebagai seorang abdi dari tokoh utama cerita tersebut, yaitu sahadewa dari keluarga Pandawa. Dengan posisi sebagai punakawan itu, Semar tidah hanya menjadi seorang abdi namun juga sebagai penebar humor, candaan, dan pemecah ketegangan di dalam suatu cerita.

Dalam kakawin Gathhotkacasraya, Empu Panuluh sudah memperkenalkan punakawan bernama Juru Deh, Punta, dan Prasanta. Tetapi, peranannya belumlah menonjol. Pada zaman Mahapahit inilah muncul Semar sebagai punakawan yang lebih berkesan dibandingkan Juru Deh, Punta, dan Prasanta. Di situ, telah jelas peranan Semar sebagai punakawan dan pelawak (Muljana, 2006).

Sementara, naskah Purwacarita mengisahkan bahwa Sang Hyang Tunggal menikah dengan Dewi Rekatawati, putra sang Hyang Rekatama. Dari perkawinan itu, lahir sebutir telur yang bercahaya. Sang Hyang Tunggal, dengan perasaan kesal, membanting telur itu sehingga pecah menjadi tiga bagian, yaitu cangkang, putih, dan kuning telur. Ketiganya masing-masing menjelma menjadi laki-laki. Yang berasal dari cangkang diberi nama Antaga, yang berasal dari putih telur diberi nama Ismaya, sedangkan yang berasal dari kuningnya diberi nama Manikmaya.

Pada suatu hari, Antaga dan Ismaya berselisih karena masing-masing ingin menjadi pewaris tahta kahyangan. Keduanya pun mengadakan perlombaan menelan gunung. Antaga berusaha melahap gunung tersebut dengan sekali telan, tapi justru mengalami musibah. Mulutnya robek dan matanya melebar. Ismaya menggunakan cara lain, yaitu dengan memakan gunung tersebut sedikit demi sedikit. Setelah melewati beberapa hari, seluruh bagian gunung pun berpindah ke dalam tubuh ismaya, tapi tidak berhasil ia keluarkan. Sejak saat itu, Ismaya pun bertubuh bulat. Sang Hyang Tunggal murka mengetahui ambisi dan keserakahan kedua putranya itu. Mereka pun dihukum menjadi pengasuh keturunan Manikmaya, yang kemudian diangkat sebagai raja kahyangan, bergelar Batara Guru. Antaga dan Ismaya pun turun ke dunia. Masingmasing memakai nama Togog dan Semar.

Semar memiliki beberapa sifat: wijaya(bijaksana dalam berbakti kepada Negara), mantriwira(dengan senang hati berbakti kepada Negara), wicaksana maya(bijaksana dalam berbicara dan bertindak), matangwan(dikasihi dan dicintai rakyat), satya bakti prabu(setia kepada Negara dan raja), wakniwak(tidak berpura-pura), seharwan pasaman(sabar dan sareh, tidak gugup dalam hati), dirut saha(jujur, teliti, sungguh-sungguh dan setia), tan lelana(baik budi dan mengendalikan panca indera), diwiyacita(menghilangkan kepentingan pribadi), masisi samastha buwana(memperjuangkan kesempurnaan diri dan ke-sejahteraan dunia) (Sungaidi, 2019). Dalam seni pewayangan kehadiran Semar sangat diidolakan oleh para penonton. Pikiran, ucapan dan tindakan Semar dianggap pantas untuk diperhatikan, diteladani dan diterapkan dalam kehidupan sehari-hari (Izzati, 2016).

Melihat peran tokoh Semar yang menonjol jika ditilik melalui fungsi yang mengiringi penanda pembukaan dan penutup pergelaran lakon, terdapat indikasi bahwa tokoh tersebut secara naratif memiliki peran dan fungsi yang penting pula (Christianto, 2003). Penelitian ini membahasa mengenai tokoh wayang Semar sebagai kekayaan yang mampu menimbulkan imajinasi dan daya kreatif dalam penciptaan karya desain komunikasi visual.

\section{METODE}

Berbeda dengan pendekatan positivistik, metode kualitatif mengadopsi apa yang disebut sebagai pandangan ontologispengakuan bahwa realitas tidak objektif. Jika dikaitkan dengan komentar Devine yang telah disebut bahwa periset perlu masuk dalam setting sosial dari fokus riset-kita bisa memulai memahami bahwa konteks adalah aspek utama di balik riset kualitatiaf : apa yang sebenarnya kita cari jawabannya adalah bukan hanya "apa yang terjadi", tetapi juga "mengapa" dan "bagaimana".

Spesifikasi dalam penelitian ini menggunakan deskriptif eksplorasi, yaitu menguraikan hasil-hasil penelitian sesuai dengan permasalahan dan tujuan yang akan 
dicapai serta menganalisanya dari segi keilmuan yang berlaku kemudian mengungkapkan sesuatu yang baru dari penelitian.

Pendekatan penelitian ini menggunakan hermeneutika hermeneutika merupakan ilmu untuk memahami atau mengerti makna tersebut. Persoalannya, apa yang dimaksud dengan mengerti atau memahami itu? Menurut Gadamer, memahami itu artinya memahami melalui bahasa. Inilah awalnya Gadamer memandang peran penting bahasa dalam proses "memahami." Jadi, proses penafsiran berawal dari penafsir hingga ke teks, dan dari penafsir ke teks melalui konteks sejarah dan cultural untukk menangka kembali maksud penulis aslinya. Menurut Schleiermacher, hasil interpretasi akan semakin baik jika penafsir mengetahui latar belakang sejarah pengarang teks, sebagaimana dinyatakan Thiselton "The more we learn about an author, the better equipped we are for interpretation (Raharjo, 2008).

Dalam penelitian ini menggunakan penetapan sampel dengan cara nonprobabilitas sampling atau nonrandom sampling dengan pengambilan sampel secara purposive sampling disesuaikan dengan tujuan penelitian. Ukuran sampel tidak dipersoalkan. Sampel yang diambil hanya yang sesuai dengan tujuan penelitian.

Pengumpulan data dilakukan dengan studi pustaka meliputi sumber yang relevan dengan permasalahan; catatan transkrip, buku, surat kabar, majalah, agenda, arsip, dan pustaka lainnya. Studi pustaka dilakukan melalui tahap-tahap identifikasi pustaka sumber data, identifikasi bahan yang diperlukan, dan inventarisasi bahan (data) yang diperlukan tersebut. Data yang sudah terkumpul kemudian diolah melalui tahap pemeriksaan (editing), penandaan (coding), penyusunan (reconstructing), sistematisasi berdasarkan pokok bahasan dan subpokok bahasan yang diidentifikasi dari rumusan masalah (systematizing). Dokumentasi dilakukan untuk mendapatkan data dengan memanfaatkan data sekunder yang sudah tersedia atau terolah. Data sekunder ini antara lain berupa dokumen-dokumen resmi organisasi pemerintah maupun dokumen institusi lain. Wawancara untuk menggali informasi tentang tokoh wayang semar dan makna filosofinya dengan dua orang dalang (Ki Sudarwo dan Ki Suryo Manggolo).

Model analisis menggunakan model interaktif Miles dan Huberman meliputi: reduksi data, sajian data, dan penarikan kesimpulan. Pembuktian validitas data penelitian ini ditentukan oleh kredibilitas temuan dan interpretasinya dengan mengupayakan temuan dan penafsiran yang dilakukan sesuai dengan kondisi yang senyatanya dan disetujui oleh subjek penelitian. Agar kondisi di atas dapat terpenuhi dengan cara memperpanjang observasi, pengamatan yang terus-menerus, triangulasi dan membicarakan hasil temuan dengan orang lain, dan menggunakan bahan referensi. Adapun untuk reliabilitas dapat dilakukan dengan pengamatan sistematis, berulang, dan dalam situasi yang berbeda.

\section{HASIL DAN PEMBAHASAN Asal Usul Semar Menurut Mitologi Jawa}

Diceritakan bahwa Batara Guru (Manikmaya), sebagai putra bungsu Sang Hyang Tunggal, measa dirinya paling cakap dan sempurna dibandingkan kedua kakaknya. Hal ini memunculkan perasaan bahwa dirinyalah yang paling pantas meneruskan kepemimpinan ayahnya sebagai raja para dewa. Dengan kecerdikannya (atau kelicikan), Batara Guru mengajak Batara Ismaya dan Batara Antaga unuk berkompetisi menguji kesaktian masing-masing. Barang siapa mampu menelan sebuah gunung dan memuntahkannya kembali, maka dia yang berhak menjadi raja para dewa. Karena kasih sayang kepada adik bungsunya dan mungkin juga didorong oleh ambisi menjadi penguasa, kedua saudaranya menyanggupi tantangan tersebut. Padahal, gunung, adalah simbol dari paku bumi yang akan menjaga kestabilan dunia dan tiang langit dan bumi. Jadi, sekalipun ditelan dan dimuntahkan lagi, sebenarnya hal terebut tidak boleh dilakukan (Sudarwo, 2020).

Perbuatan Batara Ismaya dan Batara Antaga tersebut menyebabkan Sang Hyang Tunggal marah dan menitahkan mereka untuk turun ke alam marcapada atau mayapada (bumi) yang saat itu diramalkan akan rusuh oleh pertempuran antara satria baik melawan satria berwatak buruk. Menyadari kesalahan 
masing-masing, maka mereka berdua turun ke bumi. Semar membimbing para satria berwatak baik dan Togog membimbing para satria berwatak angkara (Menggolo, 2020).

\section{Perwujudan Tokoh Wayang Semar}

Di dalam pementasan wayang, tokoh Semar memiliki bentuk fisik yang sangat unik, seolah-olah ia merupakan simbol penggambaran jagat raya. Tubuhnya yang bulat merupakan simbol dari bumi, tempat tinggal umat manusia dan makhluk lainnya.

Semar memiliki kelebihan-kelebihan, di antaranya sebagai berikut (Sudarwo, 2020):

1. Memiliki pusaka ampuh bernama Hyang Jamus Kalimasada yang dititipkan kepada Yudhistira dan merupakan pusaka utama para Pandawa. Istilah Pusaka Hyang Kalimusada merrupakan perlambang dua kalimat syahadat. Tokoh ini Bersama tokoh punakawan lainnya dibuat oleh para wali, di antaranya Sunan Kalijaga untuk menyebarkan agama Islam di Jawa melalui akulturasi budaya. Dengan adanya tokoh punakawan, pergelaran cerita wayang menjadi lebih hidup karena ada dialog dan interaksi antara dalang (wayang) dan pemirsa, juga memberikan "kesempatan" bagi para dalang untuk menyampaikan nasihat yang lebih mudah dicerna oleh orang awam.

2. Memiliki Wahyu Tejamaya yang sangat diperebutkan oleh Pandawa maupun Kurawa. Siapa saja yang hendak memimpin alam ini, sebaiknya menguasai Wahyu Tejamaya

Karena Semar telah menelan Gunung Jamurdipa, maka ada yang menganggap bahwa Semar merupakan lambang dari alam semesta. Dengan kata lain, Semar dianggap sama dengan akal budi Ratu Adil. Meskipun peranan Semar sebagai pembantu, perbuatannya menunjukkan bahwa ia adalah tokoh utama atau pokok dan bukanlah merupakan tokoh marginal atau kecil tak berarti.

Dari bentuknya saja, tokoh ini memang sulit atau tidak mudah untuk diterka. Wajahnya adalah laki-laki, tapi badannya serba bulat, berpayudara montok layaknya seorang wanita. Rambutnya putih dan kerut wajahnya menunjukkan bahwa ia telah berusia lanjut, tapi rambutnya dipotong kuncung seperti anakanak. Semar selalu tersenyum, tapi bermata sembab, sebagai simbol suka dan duka. Wajahnya tua, tapi potongan rambutnya bergaya kuncung seperti anak kecil, sebagai simbol tua dan muda. Dia berkelamin laki-laki, tapi memiliki payudara seperti perempuan, sebagai simbol pria dan wanita. Ia penjelmaan dewa, tetapi hidup sebagai rakyat jelata, sebagai simbol atasan dan bawahan.

Ciri yang menonjol dari Semar adalah kuncung putih di kepala sebagai simbol dari pikiran, gagasan, yang jernih, atau cipta. Kuncung di kepala adalah pelambang bahwa manusia haruslah menggunakan akal budinya dalam menimbang semua permasalahan. Bibirnya berkulum senyum, namun matanya selalu mengeluarkan air mata. Ia menggunakan kain sarung bermotif kawung, memakai sabuk tampar layaknya pakaian yang digunakan oleh kebanyakan abdi.

Semar berperut besar, artinya memiliki wawasan yang luas. Jari tangannya selalu menunjuk, melambangkan bahwa ia selalu memberikan petunjuk kepada semua orang yang memintanya. Jambul/kuncung yang dimilikinya memberikan perlambang kesaktian. Ia bisa mengetahui hal yang belum terjadi, dalam pengertian, ia selalu waspada (Menggolo, 2020). Dengan bentuk dan gambaran yang demikian, semar, selain sebagai sosok yang syarat misteri, juga sebagai simbol kesempurnaan hidup. Di dalam Semar, terdapat karakter wanita, laki-laki, anak-anak dan orang dewasa atau orang tua. Ekspresi gembira dan ekspresi sedih bercampur menjadi satu.

Kesempurnaan tokoh Semar menjadi lengkap dengan jimat Mustika Manik Astagina, pemberian sang Hyang Wasesa atau Sang Hyang Tunggal yang disimpan di kuncungnya. Jimat tersebut mempunyai delapan daya, yaitu terhindar dari lapar, mengantuk, asmara, sedih, capek, sakit panas, dan dingin. Delapan khasiat dari jimat Mustika Manik Astagina tersebut dimaksudkan untuk menggambarkan walaupun Semar hidup di dalam alam kodrat, ia berada di atas kodrat itu sendiri. Ia adalah simbol misteri kehidupan sekaligus kehidupan itu sendiri. Jika kita memahami hidup merupakan anugerah dari 
sang Maha Hidup, maka Semar merupakan anugerah sang Maha Hidup yang hidup dalam kehidupan nyata.

Secara umum, bentuk penggambaran ciri-ciri sosok Semar dalam wayang kulit sebagai berikut:

1. Semar berkuncung seperti kanakkanak, tapi juga berwajah sangat tua.

2. Saat Semar tertawa, selalu diakhiri nada tangisan.

3. Mata Semar terlihat menangis, tapi mulutnya tertawa.

4. Semar berprofil berdiri sekaligus jongkok.

5. Semar tak pernah menyuruh, tapi memberikan konsekuensi atas nasihatnya.

Semar, dalam bahasa Jawa, disebut juga sebagai dempel yang artinya keteguhan jiwa. Rambut Semar berbentuk seperti kuncung yang bermakna akuning sang kuncung, yaitu sebagai kepribadian pelayan yang mengejawantah untuk melayani manusia. Dia tidak laki-laki dan bukan perempuan. Tangan kanannya ke atas mempunyai makna bahwa sebagai pribadi, tokoh Semar hendak mengatakah simbol sang Maha Tunggal. Sedangkan tangan kirinya ke belakang mengandung makna berserah total dan mutlak serta sekaligus simbol kemuliaan yang netral tapi simpatik.

Kenapa Semar mempunyai senjata kentut dan bukan senjata yang bersifat fisik, seperti panah, pedang, tombak ataupun sejenisnya? Alasannya sebagai berikut (Sudarwo, 2020):

1. Kentut berasal dari dalam diri Semar sendiri. Jadi, senjata ini sifatnya adalah kekuatan yang muncul dari pribadi Semar, bukan alat yang diciptakan atau dibuat.

2. Semar menggunakan senjatanya bukan untuk mematikan, tapi lebih untuk menyadarkan. Dalam beberapa lakon atau cerita pewayangan, Semar menggunakan kentutnya untuk melawan resi, raja, atau satria yang tidak bisa dikalahkan oleh Pandawa Lima. Mereka akhirnya badar atau sadar kembali pada perwujudannya semula.

3. Semar akan menggunakan senjata kentutnya apabila para raja atau satria asuhannya tidak bisa mengatasi masalah dengan cara yang konvensional atau hanya menggunakan senjata biasa. Sebagai makna simbolik, kentut sendiri mempunyai nuansa bersuara dan berbau busuk atau tidak enak. Jadi, kentut juga bisa berarti suara yang berbau atau bernuansa kurang enak didengar maupun dirasakan.

Kalau kita kombinasikan kentut dengan simbollik Semar sebagai suara rakyat kecil yang bercirikan kesederhanaan, maka senjata kentut Semar bisa mempunyai arti simbolik suara rakyat yang menyuarakan kebenaran, yang bersifat memberikan kesadaran kepada para pimpinan agar kembali pada jalan yang benar. Dengan demikian, suara rakyat, bagi sang pimpinan, adalah suara yang tajam dan tidak enak didengar dan kalau dirasakan berbau busuk karena keterus terangan melakukan kritik. Kenyataaannya, apabila rakyat sudah mengutarakan isi hatinya, apalagi kalau menyampaikan kemarahannya, akan lebih dahsyat laiknya kentut Kiai Semar. Sehingga, mau tidak mau, pemimpin harus sadar untuk memperbaiki diri atau sadar bahwa kepemimpinannya sebetulnya tidak diakui oleh mayoritas rakyat dan rakyat mengakuinya semata-mata berdasarkan rasa ketakutan. Sadar jika kepemimpinannya tidak diakui oleh mayoritas rakyat dan rakyat mengakuinya semata-mata berdasarkan rasa takut, bukan tidak mungkin bisa terjadi suatu kondisi people power atau kekuatan rakyat.

Semar bukan lelaki dan bukan perempuan, tangan kanannya ke atas dan tangan kirinya ke belakang. Maknaya adalah sebagai pribadi, tokoh Semar hendak mengatakan simbol Sang Maha Tunggal. Sedang tangan kriinya bermakna berserah total dan mutlak serta sekaligus simbol keilmuan yang netral namun simpatik. Gambar Semar yang sedang menunjuk dengan jari telunjuk melambangkan bahwa ia memberikan petunjuk pada manusia kalau hanya ada satu sesembahan, yaitu Allah Hyang Maha Kuasa. Semar menggenggam tangan kirinya mengkiaskan bahwa ia telah memiliki keluhuran. Ia memakai kelintingan, memberikan tanda agar orang mendengar bila telah dibunyikan. Semar memakai pusaka menunjukkan bahwa tutur katanya (sabdanya) 
selalu suci. Lipatan kainnya berjumlah lima, menunjukkan bahwa ia telah memiliki dan dapat menjalani lima sifat Allah: Agung, Rahim, Adil, Wasesa, dan Langgeng.

\section{Semar Sebagai Budaya Lokal yang Memperkaya Imaginasi dan Daya Kreatif}

Menurut Widagdo (1993:31) desain komunikasi visual dalam pengertian modern adalah desain yang dihasilkan dari rasionalitas. Dilandasi penggetahuan, bersifat rasional, dan pragmatis. Jagat desain komunikasi visual senantiasa dinamis, penuh gerak, dan perubahan. Hal itu karena peradaban dan ilmu pengethuan modern memungkinkan lahirnya industrialisasi. Sebagai produk kebudayaan yang terkait dengan sistem sosial dan ekonomi, desain komunikasi visual juga berhadapan pada konsekuensi sebagai produk massal dan konsumsi massa.

Terkait dengan itu, Sutanto (2005: 1516) menyatakan, desain komunikasi visual senantiasa berhubungan dengan penampilan rupa yang dapat diserap orang banyak dengan pikiran maupun perasaannya. Rupa yang mengandung pengertian atau makna, karakter serta suasana, yang mampu dipahami (diraba dan dirasakan) oleh khalayak umum atau terbatas. Dalam pandangan Sanyoto (2006:8) desain komunikasi visual memiliki pengertian secara menyeluruh, yaitu rancangan sarana komunikasi yang bersifat kasat mata.

Wayang semar memang hanyalah selembar kulit kerbau atau lembu. Tetapi, dia merupakan suatu macam simbol atau lambang yang sangat berharga untuk dipelajari secara mendalam dan seksama. Huruf dan gambar adalah simbol untuk bahasa, sedangkan bahasa adalah simbol bagi manusia. Apakah sebenarnya simbol atau lambang itu? Lambang adalah sarana atau alat bagi konsepsi manusia tentang objek. Karena itu, simbol juga merupakan suatu representasi mental atau pengejawantahan jiwa dari subjek atau wujud konsepsi dari manusia. Karenanya, lambang selalu menunjukkan pada konsep.

Karena simbolisasi adalah esensial atau kegiatan inti dari budi manusia, maka dengan simbolisasi itu pula akan diketemukan suatu kunci pemecahan masalah hakiki dari manusia yang memilikinya, baik tentang hal yang bersifat fisik maupun yang nonfisik, seperti mental, religi, mitos, ritual, karya seni, upacara peribadatan, dan lainnya. Di sinilah letak arti dari lambang wayang Semar. Wayang Semar adalah lambang yang mempunyai sifat esoteris. Oleh karena itu, dengan mepelajari tokoh wayang Semar, dihadarpkan dapat diketahui dan dipahami tentang peribadatan, mitos ritual, religi, watak, dan sifat dari para pendukungnya.

Fungsi punakawan Semar adalah untuk memperagakan fungsi dan tugas konsepsional Wali Sanga dan para mubaligh Islam sebagai syiar Islam. Wayang Semar adalah tokoh wayang yang lain daripada yang lain. Hampir dapat dikatakan bahwa orang yang berkenalan dengan wayang pasti mengenal Semar karena tokoh ini selalu menarik perhatian serta sangat berharga untuk dipelajari dengan seksama dan sedalamdalamnya.

Mengapa tokoh yang satu ini banyak dipertanyakan? Hal ini dikarenakan tokoh Semar dianggap memiliki nilai lebih dalam mitologi masyarakat Jawa dan tentu saja kandungan filosofis yang melekat pada dirinya. Dorongan untuk mengkaji dan mengupas dalam tataran filsafat timbul dikarenakan keinginan untuk berpikir secara lebih tertib dalam paparan teoretis dan ilmiah. Pemahaman filosofis tersebut juga berarti bahwa kita telah berani untuk melangkah maju, bahkan melompat dari wilayah mitos ke wilayah logos agar dapat mengetahui rahasia tentang kehidupan dan alam semesta secara lebih mendalam. Mitos sendiri sebenarnya tidak bertentangan dengan logos dikarenakan ia tidak mutlak bertentangan dengan rasio. Ada hal-hal mitologis yang justru memiliki unsur kebenaran yang dapat dipergunakan dalam menjabarkan hal-hal filsafat.

Dalam ilmu pengetahuan, sering kali rasio menemui keterbatasan yang akhirnya tidak dapat dilampai lebih lanjut. Dalam kesempatan itu, maka mitos akan memberanikan diri untuk masuk ke wilayahwilayah yang belum atau tidak dikenal itu. Mitos pun kemudian digunakan untuk mengemukakan dugaan-dugaan yang berurusan tentang hal-hal yang nirrupa, abstrak, tanpa fisik, nonwujud, kejiwaan, atau bersifat ruhaniah. Hingga kini, logos dan mitos pun berjalan sejajar di mana pada suatu saat, keduanya akan saling melengkapi dan bertemu 
pada sebuah titik untuk saling mengisi sehingga mitologi pun tidak mutlak bertentangan dengan filsafat.

Ajaran tua tentang kekuasaan politik bersumber dari Hastabrata, dan dimitoskan dalam diri Semar yang paradoks. Etika kekuasaan ada dalam diri tokoh Semar. Dia adalah dewa tua, tetapi menjadi hamba. Dia berkuasa, tetapi melayani. Dia kasar di kalangan atas, tetapi halus di kalangan bawah. Dia kaya raya penguasa semesta, tetapi memilih makanan sisa. Dia marah kalau kalangan atas bertindak tidak adil. Dia menyindir dalam bahasa metafora apabila yang dilayaninya berbuat salah. Bentuk badan Semar juga paradoks, seperti perempuan tetapi juga mirip lelaki, kombinasi ketegasan dan kelembutan.

Dalam bahasa Jawa (filosofi Jawa), Semar disebut Badranaya. Bebadra artinya membangun sarana dari dasar, naya ata nayaka artinya adalah utusan mangrasul. Sehingga, arti Badranaya adalah mengemban sifat membangun dan melaksanakan perintah Allah demi kesejahteraan manusia. Dalam pandangan Javanologi, Semar berasal dari kata haseming samar-samar, yaitu fenomena harfiah makna kehidupan Sang Panuntun.

Disebutkan oleh Dr. Pegeaud, tugas Semar bukan hanya sebagai inisiator atau pengesah dalam penobatan raja saja, tetapi juga merangkap sebagai perantara, pemuka, dan pelindung yang turut mengabdi kepada satria momongannya. Ia juga berpendapat bahwa Semar adalah makhluk hermaphrodite, artinya berkelamin ganda, bisa berperan sebagai lelaki dan juga sebagai perempuan atau keduaduanya alias wandu (banci). Namun, pendaptanya yang terakhir ini disangkal oleh para pendukung wayang, khususnya para dalang Jawa. Hal ini didasarkan pada tembang pocung yang menggambarkan sosok Kiai Lurah Semar, yaitu luwih ewuh Lurah Semar. Yen ginunggung, yen jalua samara, jaja mungal lir pawestri. Yen estria pun semar kekuncungan (sungguh sulit untuk menggambarkan Kia Lurah Semar. Kalau ia seorang lelaki sungguh sangat meragukan karena ia mempunyai dada yang menonjol seperti wanita. Kalau ia seorang wanita, tapi berkuncung).

Dari tembang tersebut dapat digambarkan bahwa tidak ada tanda-tanda untuk menunjukkan sifat kebancian di dalam diri Semar. Yang ada hanyalah petunjuk tentang kegaiban atau kemisteriusannya sehingga dikatakan bahwa semar itu tan kena kinayangapa, artinya tak dapat digambarkan dengan kata-kata atau tak bisa diumpamakan dengan siapa, apa, dan bagaimanapun karena Semar bukan laki-laki, juga bukan perempuan, dan bukan pula sebagai seorang banci. Semar selalu hadir dalam setiap lakon wayang dan kehadirannya sangat dinanti para penggemarnya. Meskipun dia seorang abdi, rakyat jelata, buruk rupa, miskin, hitam legam, tapi di balik wujud lahirnya tersebut tersimpan sifat-sifat mulia, yakni mengayomi, mampu menyelesaikan masalah, sabar, dan bijaksana.

Bocah bajang nggiring angina, anawu banyu segara, ngon-ingone kebo dhungkul, sa sisih sapi gumarang.

Teks tersebut menggambarkan bocah bajang, yaitu anak yang tidak bisa besar atau cacat, merupakan salah satu jineman atau lagu yang selalu dikumandangkan pada pergelaran wayan gpurwa, khusus untuk mengiringi munculnya tokoh Semar pada waktu gara-gara. Hal tersebut tidak secara kebetulan, tetapi merupakan sebuah ekspresi kreatif untuk menyampaikan sesuatu makna yang dianggap penting melalui lagu "bocah Bajang" dan wayang Semar.

Tokoh semar mempunyai sifat pribadi yang mendua. Ia adalah dewa bernama Batara Ismaya, yang menitis (tinggal dan hidup) pada seorang manusia cebol dan berkulit hitam bernama Ki Semarasanta. Bentuk wayangnya pun dibuat mendua. Bagian kepala adalah lakilaki, tetapi payudara dan pantatnya adalah perempuan. Rambutnya dipotong kuncung seperti anak-anak, tetapi sudah memutih seperti orang tua. Bibirnya tersenyum menggambarkan kegembiraan dan kebahagiaan, tetapi matanya selalu basah seperti sedang menangis sedih.

Sebuah dugaan, tokoh Semar, dalam pewayangan, merupakan perwujudan dari kerinduan manusia dalam pengembaraannya menyelami yang ilahi. Dikarenakan Hyang Maha Sempurna itu tidak kelihatan, tidak bisa diraba, jauh tak terbatas, dekat tidak bersentuahan, maka kekurangan, kelemahan, dan kecacatannya, manusia hanya dapat menggambarkan ketidakmampuannya menggambarakan Yang Ilahi. Maka, yang 
muncul kemudian adalah bentuk yang tidak sempurna (Kresna, 2015).

Lahirnya karya yang disengaja tidak sempruna seperti wayang Ki Semarasanta atau Semar merupakan sebuah konsep kerendahan hati, penyadaran diri, dan keterbukaan pribadi akan kelemahan, kekurangan, dan cacatcacatnya. Karena dengan sikap tersebut, manusia diyakini mampu nglenggahake atau menghadirkan dan mendudukkan Yang Maha Sempurna. Dalam istilah pewayangan, terdapat makna sinonim dari wulucumbu, yakni rambut yang tumbuh pada jempol kaki. Keseluruhan gambaran karakter pribadi Ki Lurah Semar tersebut berguna dalam upaya melestarikan alam semesta dan menciptakan kemakmuran serta kesejahteraan di bumi pertiwi.

Sementara itu, dalam istilah pewayangan yang dibawakan oleh Kanjeng Sunan Kalijaga, Semar adalah gubahan dari lafazh sinaar, yang berarti paku atau penancap. Hal ini menunjukkan bahwa seorang muslim haruslah menjadi paku. Seorang muslim yang baik harus siap untuk dipukul guna merekatkan kayu dan menyembul keluar dari kayu. Ini menyiratkan bahwa seorang muslim haruslah bisa menjadi mediator (penyambung) dari semua golongan tanpa pandang bulu.

Jika Sunan Kalijaga diyakini sebagai pencipta tokoh punakawan itu sebagai salah satu upaya untuk menyebarkan agama Islam di tanah Jawa, maka ia pun mempergunakan hakikat yang tersirat dalam menjalankan aktivitas tersebut agar misinya bisa terlaksana dengan sebaik baiknya. Sudah barang tentu mengaitkan nama tokoh tersebut disesuaikan dengan tujuan dan karakter yang bersangkutan.

Semar berasal dari kata Arab, yaitu simaar ata ismarun yang artinya paku. Paku adalah alat untuk menancapkan suatu barang agar tegak, kuat, dan tidak goyah. Semar juga memiliki nama lain, yaitu Ismaya, yang berasal dari kata "asma-Ku" atau symbol kemantapan dan keteguha. Karena itu, usaha yang dilakukan harus didasari keyakinan yang kuat agar usaha tetancap sampai mengakar.

Nala Gareng sejatinya berasal dari kata naala qarin yang artinya memperoleh banyak kawan atau memperluas persahabatan. Sedangkan petruk di adaptasi dari kata fatruk yang artinya "tinggalkan yang jelek". Selain itu, Petruk juga sering disebut Kanthong Bolong, artinya kantong yang berlubang.
Maknanya, setiap manusia harus mengamalkan hartanya yang berlebih kepada sesame dan menyerahkan jiwa raganya kepada Yang Maha Kuasa secara ikhlas, tanpa pamrih dan ikhlas, seperti bolongnya kantong yang tanpa penghalang. Sejalan dengan orang berusaha, sikap kemantapan dan keteguhan yang tanpa pamrih dan ikhlas niscaya akan memberikan hasil yang terbaik. Sayangnya, banyak orang yang mengartikan terbaik itu adalah mendapatkan atau memperoleh sesuatu, padahal tidak selalu begitu.

Tokoh yang terakhir, Bagong, berasal dari kata bagha yang artinya pertimbangan makna dan rasa antara yang baik dan buruk, benar dan salah. Dalam versi lain, kata Bagong berasal dari Baqa' yang berarti kekal atau langgeng. Sama halnya dengan sikap introspeksi yang terus menerus walau sudah terasa nyaman di badan agar usaha yang dilakukan bisa kekal dan langggeng karena usaha itu penuh dengan ketidakpastian.

Dalam perspektif spiritual, Semar mewakili watak yang sedehana, tenang, rendah hati, tulus, tidak munafik, tidak penah terlalu sedih, dan tidak pernah tertawa terlalu riang. Keadaan mentalnya sangat matang, tidak mudah kaget, dan tidak gampang heran. Semar bagaikan air tenang yang menghanyutkan. Di balik ketenangan sikapnya, tersimpan kejeniusan, ketajaman batin, pengalaman hidup, dan ilmu pengetahuan.

Semar menggambarkan figure yang sabar, tulus, pengasih, pemelihara kebaikan, penjaga kebenaran, dan selalu menghindari perbuatan dur angkara. Semar juga dijuluki Badranaya. Badra adalah rembulan, sedangkan naya adalah wajah. Atau, Nayantaka. Naya adalah wajah, dan taka berarti pucat. Keduanya berarti menyimbolkan bahwa Semar memiliki watak rembulan (dalam Pustaka Hasta Brata) dan seorang figur yang memiliki wajah pucat. Artinya, Semar tidak mengumbar hawa nafsu.

Semareka den prayitna. Semare artinya menidurkan diri agar batin selalu awas. Maka, yang ditidurkan adalah panca indranya dari gejolak api atau nafsu negatif. Inilah nilai di balik kalimat wani mati sajroning urip (berani mati di dalam hidup). Perbuatannya selalu netepi kodrat Hyang Widi (pasrah), dengan cara mematikan hawa nafsu negatif. Sikap demikian akan diartikulasikan ke dalam sikap watak kita sehari-hari dalam pergaulan. 
Pucat (dingin) alias tidak mudah emosi, tenang dan berwibawa, tidak gusar dan gentar jika dicaci-maki, tidak lupa diri jika dipuji, sebagaimana watak badranaya atau wajah rembulan.

Dalam khazanah spiritual Jawa, khususnya mengenai konsep manunggaling kawula-Gusti, Semar dapat menjadi personifikasi hakikat guru sejati setiap manusia. Semar adalah samar-samar sebagai perlambang guru sejati atau sukma sejati yang wujudnya samar, bukan nyata atau wadag dan tak kasat mata. Sedangkan Pandawa Lima adalah personifikasi jasad (badan) yang di dalamnya terdapat pancaindra.

Karena sifat badan cenderung lengah dan lemah, maka sebaik apapun jasad seorang satria, tetap saja ia harus diasuh dan diawasi oleh sang guru sejati agar senantiasa eling lan waspadha dan badan memiliki keteguhan pada ajaran kebaikan sang guru sejati. Guru sejati merupakan pengendali seseorang agar tetap dalam laku (perbuatan) yang tepat (pener) dan berada pada koridor bebener (kebaikan).

Semar sendiri mempunyai ciri umum bahwa dia hanya memberi nasihat tanpa menyuruh atau memaksa. Semua diserahkan kembali kepada yang diayominya. Di daerah pantura (pantai laut utara) dan sekitar Cirebon, Semar juga dikenal dengan sebutan Radenwati Kuncung Putih Paku ning Alam, Radenwati Kuncung Kuning Paku ning Alam, dan Radenwati Kuncung Hitam Paku ning Alam.

\section{SIMPULAN DAN SARAN}

Masalah lokalitas budaya lokal Indonesia pelu digarisbawahi di sini. Karena budaya lokal Indonesia perlu dirangkul menjadi kekayaan imajinasi dan sumber kreativitas bagi proses penciptaan karya desain iklan baik di lingkungan pendidikan periklanan maupun bagi insan kreatif professional di industri periklanan Indonesia. Dengan mengikuti perilaku adat istiadat yang berlaku, menjunjung tinggi moralitas, dan mengedepankan kearifan budaya lokal untuk kemudian diangkat menjadi inspirasi, sumber ide, dan gagasan, serta sebagai perangkat lunak untuk mengomunikasikan beragam pesan komersial, sosial, ataupun moral kepada sasaran khalayak yang dibidik, maka berbagai karya desain komunikasi visual yang dihasilkan oleh tangan-tangan kreatif yang senantiasa mengedepankan kearifan budaya lokal Indonesia akan menjadi penanda yang cukup kuat. Dengan demikian, keberadaan sebuah karya desain komunikasi visual akan memberikan aksentuasi perikehidupan masyarakat, ujung-ujungnya diharapkan mampu mencerahkan pemikiran dan perasaan umat manusia yang hidup dan mengisi kehidupannya sesuai dengan talenta masingmasing. Tokoh wayang Semar yang penuh misteri juga merupakan bagian dari tokoh mitologis religious yang disayangi oleh masyarakat Jawa pada khususnya. Oleh karena itu, Semar dianggap memiliki nilai dan berharga tinggi dalam pewayangan sebagai bagian dari kehidupan masyarakat Jawa. Maka, tentu saja tokoh Semar akan menarik untuk dipelajari dengan lebih seksama dan lebih mendalam dari sisi falsafah dalam upaya mengungkap misteri yang menyelubunginya.

\section{DAFTAR PUSTAKA}

Christianto, Wisma Nugraha. (2003). Peran dan Fungsi Tokoh SemarBagong dalam Pergelaran Lakon Wayang Kulit Gaya Jawa Timuran. Humaniora, 15(3), 285-301.

Fauzan, Rikza \& Nashar. (2017). Memperhatikan Tradisi, Melestarika Budaya: Kajian Historis dan Nilai Budaya Lokal Kesenian Terebang Gede di Kota Serang. Jurnal Candrasangkala, 3(1), 1-9.

Herliyani, Elly \& Suryana, Jajang. (2015). DKV Sebagai Perancangan Media Promosi Jurusan Desain Komunikasi Visual (DIII) Undiksha Berbasis Web. PRASI, 10(20), 61-73.

Izzati, Afina. (2016). Nilai-Nilai Konstruk Harmoni: Perspektif Tokoh Wayang Semar. Fikrah: Jurnal Ilmu Aqidah dan Studi Keagamaan, 4(2), 261-275.

Kresna, Ardian. (2012). Dunia Semar. Yogyakarta: DIVA press. 
Menggolo, Ki Suryo. (2020). Penokohan Wayang Semar dalam Pagelaran Wayang Kulit. Wawancara tanggal 23 September 2020.

Muljana, Slamet. (2006). Nagarakretagama dan Tafsir Sejarahnya. Jakarta: Bhatara.

Pusat Pendidikan Desain Komunikasi Visual Modern. (2020). File://C:/Users/ASUS/Downloads/ 2TA13262.pdf, diakses 2 November 2020 pukul 10.00.

Raharjo, Mudjia. (2008). Dasar-Dasar Hermeneutika : Antara Intensionalisme dan Gadamerian. Yogyakarta: Ar-Ruzz Media.

Saini KM. (2001). Penciptaan Seni, Menapak Meninggi. Seminar Sehari tentang Penciptaan Seni, Program Pacasarjana ISI Yogyakarta.

Setyaningrum, Naomi Diyah Budi. (2018). Budaya Lokal di Era Global. Ekspresi Seni: Jurnal Ilmu Pengetahuan dan Karya Seni, 20(2), 102-112.

Sudarwo, Ki. (2020). Tokoh Wayang Semar. Wawancara tanggal 12 September 2020.

Sungaidi, Muhammad. (2019). Asketisme Semar: Pergumulan Agama-Sosial. REFLEKSI, 18(2), 181-200.

Suparno et al. (2018). Mempertahankan Eksistensi Budaya Lokal Nusantara Ditengah Arus Globalisasi melalui Pelestarian Tradisi Gawai Dayak Sintang . Jurnal PEKAN, 3(1), 4356.

Sutanto, T. (2005). Sekitar Dunia Desain Grafis/Komunikasi Visual. Purapura Jurnal DKV ITB, 15-16.

Tinarbuko, Sumbo. (2015). DEKAVE: Desain Komunikasi Visual Penanda Zaman Masyarakat Global. Yogyakarta: CAPS (Center for Academic Publishing Service).

Widagdo. (1993). Desain, Teori, dan Praktik. Seni Jurnal Pengetahuan dan Penciptaan Seni BP ISI, 3(3), 20-32. 